\title{
Pemetaan Klasifikasi Dan Analisa Perubahan Ekosistem Mangrove Menggunakan Citra Satelit Multi Temporal Di Karimunjawa, Jepara, Indonesia
}

\author{
Nurul Latifah', Sigit Febrianto*, Hadi Endrawati² dan Muhammad Zainuri ${ }^{3}$ \\ 1Departemen Sumberdaya Akuatik, Fakultas Perikanan dan Ilmu Kelautan, Universitas Diponegoro \\ 2Departemen IImu Kelautan, Fakultas Perikanan dan IImu Kelautan, Universitas Diponegoro \\ 3Departemen Oseanografi, Fakultas Perikanan dan IImu Kelautan, Universitas Diponegoro \\ Jl. Prof. Soedarto, SH. Tembalang, Semarang 50275 Indonesia \\ Email: febriantosigit40@gmail.com
}

\section{Abstract \\ Mapping of Classification and Analysis of Changes in Mangrove Ecosystem Using Multi-Temporal Satellite Images in Karimunjawa, Jepara, Indonesia}

Mangrove ecosystem is one of the three ecosystem in the coastal area which has important ecological role in supporting marine life and fisheries resources. These important roles include spawning ground and nursery ground for various marine organisms. However, in the last decades, mangrove ecosystem has been undergoing significant degradation. The aim of this research is to quantify the changes of mangrove coverage and density in Karimunjawa as well as key-factors leading to the changes. Supervised classification method $183 \%$ accuracy and Kappa coefficient $0.73 \%)$ was applied to satellite images to identify the temporal changes in mangrove coverage. Mangrove density was quantified using NDVI algorithm and NIR-RED wavelength. The result shows that during three periods of observed data, changes in mangrove coverage were significant: 126.81 ha increase (1992 - 2003); 82.37 ha decrease (1992 - 2017); and 209.18 ha decrease (2003 2017). Mangrove density in most part of Karimunjawa belongs to the category of 'low' (NDVI value: $-1-0.33)$. Key factors contributing to the decrease mangrove coverage are deforestation, natural phenomena, land conversion into fish ponds and hotels. The only increase in the year $1992-2003$ was caused by high sedimentation level that allows more mangroves to grow. Overall, the methods in this research could be used as an approach to describe to effectively monitor the changes of mangrove coverage in an area as basic data for sustainable environmental management.

Keywords : mangrove ecosystem; supervised classification; NDVl; satellite images; Karimunjawa

\begin{abstract}
Abstrak
Ekosistem mangrove merupakan salah satu dari tiga ekosistem pesisir yang memiliki peranan ekologis penting dalam mendukung kehidupan dan keberlangsungan dari sumberdaya perikanan. Hal tersebut dikarenakan fungsi mangrove sebagai tempat memijah dan asuhan bagi banyak biota air. Beberapa dekade terakhir keberadaan dari ekosisitem mangrove mengalami degradasi yang sangat signifikan. Tujuan dari penelitian ini adalah untuk mengetahui perubahan luasan dan kerapatan mangrove dan mengidentifikasi faktor penyebabnya. Metode analisa perubahan luasan mangrove menggunakan citra satelit multi temporal dengan dilakukan pembuatan klasifikasi menggunakan metode supervised classification dengan nilai akurasi total 83\% dengan Kappa koefisien $0,73 \%$. Setelah terseleksi antara mangrove dan non mangrove maka dilakukan perhitungan kerapatan tajuk menggunakan algoritma NDVI dengan memanfaatkan panjang gelombang NIR dan RED. Hasil analisa spasial dengan rentang 3 tahun berbeda
\end{abstract}


didapatkan perubahan penurunan dan penambahan luasan mangrove terjadi secara signifikan: tahun 1992 - 2003 telah terjadi penambahan luasan sebesar 126,81 ha; tahun 1992-2017 terjadi perubahan luasan sebesar 82,37 ha; tahun 2003-2017 terjadi perubahan luasan sebesar 209,18 ha. Kerapatan mangrove di Karimunjawa sebagian besar tergolong kategori kerapatan jarang dengan nilai NDVI antara -1 - 0,33. Faktor utama penyebab penurunan luasan mangrove antara lain penebangan liar, faktor alam, perubahan fungsi lahan menjadi pertambakan dan perhotelan. Penambahan luasan mangrove terjadi pada antara tahun1992 sampai 2003 hal tersebut disebabkan sedimentasi yang menumpuk di pantai dan sudah ditumbuhi oleh mangrove. Secara keseluruhan metode ini dapat menggambarkan perubahan secara efektif serta hasilnya dapat dipergunakan untuk pemantauan dan perencanaan ekosistem mangrove di suatu wilayah.

Kata kunci: ekosistem mangrove; supervised classification; NDVI; citra satelit; karimunjawa.

\section{PENDAHULUAN}

Mangrove merupakan ekosistem pesisir yang tumbuh didaerah pasang surut serta memiliki banyak fungsi satu diantaranya adalah fungsi ekologis antara lain sebagai pelindung dari erosi pantai,daerah pemijahan, dan asuhan bagi banyak biota perairan, penyerap $\mathrm{CO}_{2}$, penahan hempasan angin dan gelombang (Suratman, 2008). Luasan total mangrove eksisting yang berada di Asia sebesar 42\%, Afrika 20\%, Amerika Utara dan Amerika Tengah $15 \%$ dengan luas total mangrove seluruh dunia sebesar 16.530.000 Ha. (Giri et al., 2011). Luasan mangrove di Indonesia sebesar $23 \%$ dari luas ekosistem mangrove dunia dengan luasan sebesar 1.671.140,75 Ha dalam kondisi baik, sedangkan dalam kondisi rusak seluas 1.817.999,93 $\mathrm{Ha}$ (llman et al., 2011; Murdiyarso et al., 2015). Mangrove di Jawa Tengah berada pada kondisi baik, sedang dan rusak dengan luas total sebesar 19.645,77 Ha; luasan mangrove yang berada pada kondisi baik sebesar 14.633,93 Ha; kondisi sedang sebesar 2.069,87 $\mathrm{Ha}$; dan kondisi rusak 2.941,97 Ha (Kamal et al., 2015). Mangrove merupakan salah satu ekosistem pesisir yang paling banyak mendapatkan tekanan dan ancaman dari berbagai kegiatan.

Karimunjawa merupakan Taman Nasional yang terletak di Jawa Tengah dan merupakan daerah konservasi sehingga keberadaan ekosistem yang ada diharapkan terlindung. Ekosistem mangrove yang berada di Karimunjawa sebesar $11.177 \mathrm{Ha}$ merupakan salah satu hutan mangrove terbesar di Jawa Tengah (Kamal et al., 2016).
Banyak studi terkait ekosistem mangrove yang telah dilakukan meliputi struktur komunitas, monitoring dan deteksi mangrove menggunakan penginderaan jauh (Blasco et al., 2001; Everitt et al., 2008; Giri et al., 2007; Seto \& Fragkias, 2007; dan Polidoro, 2010). Ekosistem mangrove dapat di identifikasi menggunakan penginderaan jauh dengan menggunakan klorofil-a dan habitat hidup dari mangrove yang terletak didaerah pasut (Vo et al., 2013). Salah satu citra satelit yang digunakan adalah citra satelit Landsat, klasifikasi citra satleit Landsat yang biasa digunakan adalah resolusi spasial 30 meter dan L-band SAR (Kovacs et al., 2013; Kuenzer et al., 2011). Keunggulan lain dari satelit ini adalah resolusi temporal 16 hari serta free dalam proses pengambilan datanya (ESA, 2015). Beberapa kajian tentang ekosistem mangrove dan penginderaan jauh yang telah banyak dilakukan tidak menganalisis faktor penyebab dari kerusakan mangrove. Oleh karena tujuan dari penelitian ini adalah untuk mengetahui perubahan luasan dan kerapatan mangrove dan mengidentifikasi faktor penyebabnya.

\section{MATERI DAN METODE}

Penelitian di ekosistem mangrove Taman Nasional Karimunjawa di pulau Kemujan dan Karimunjawa yang merupakan kawasan Balai Taman Nasional Karimunjawa yang berada di Jawa Tengah dan dikelilingi oleh perairan Laut Jawa (Gambar 1). Dalam penelitian ini digunakan citra satelit multi temporal antara lain citra Landsat 5, 7, 8 dengan perekaman tahun 1992, 2003 dan 2017 serta Peta Rupa Bumi Indonesia skala 1:25.000. Software guna memproses data 
yang di dapatkan terdiri dari software Ermapper 7.0, Arcgis 10.2 dan Microsoft Office 2013.

Metode yang digunakan dalam melakukan ekstraksi ekosistem mangrove menggunakan penginderaan jauh melalui beberapa tahapan: 1). Prosesing data termasuk dengan koreksi atmosferik dan geometri, 2). Interpretasi visual mangrove, 3). Klasifikasi citra unsupervised menggunakan Support Vector Machine, NDVI (SVM), 4). Akurasi klasifikasi citra dan NDVI 5). Deteksi Perubahan Luasan Mangrove.

\section{Pre-prosesing Citra Satelit}

Citra satelit multi temporal yang digunakan adalah citra Landsat 7 ETM+ yang memiliki 8 saluran dengan resolusi temporal 16 hari dan resolusi spasial $30 \mathrm{~m}$. Selain citra satelit Landsat juga digunakan citra satelit Sentinel 2 yang memiliki resolusi temporal 10 hari dan resolusi spasial $10 \mathrm{~m}$. sebelum melakukan pengolahan tertebih dahulu dilakukan koreksi atmosferik menggunakan formula TOA serta koreksi geometri dengan menyesuaikan koordinat sesuai sistem proyeksi bumi dengan menggunakan pula peta acuan yang telah memiliki informasi koordinat (Cideciyan et al., 1992).

\section{Masking Citra}

Masking merupakan proses yang dilakukan sebelum dilakukan klasifikasi citra hal ini bertujuan untuk memisahkan obyek yang akan di analisis dengan obyek lain yang akan dihilangkan. Dalam hal ini mangrove merupakan obyek yang akan dimunculkan sedangkan obyek lain seperti vegetasi non mangrove, pemukiman, bandara, awan, dan perairan merupakan obyek yang akan dihilangkan. Untuk mengidentifikasi obyek terlebih dahulu dilakukan komposit band baik warna alami maupun warna semu 453 untuk citra Landsat 5, 7 dan 432 untuk citra Sentinel 2 (Irons et al., 2012). Seleksi citra vegetasi dan non vegetasi dilakukan menggunakan algoritma Normalized Difference Vegetation Index (NDVI) dengan didasarkan pada kisaran nilai NDVI kurang dari 0,2 akan dihilangkan.

\section{Klasifikasi Supervised Citra Satelit}

Klasifikasi supervised bertujuan untuk memisahkan piksel berdasarkan nilai spektral kemudian piksel dengan nilai spektral yang sama akan di kelompokan untuk dijadikan satu kelas. Support Vector Machine (SVM) merupakan algoritma klasifikasi non parametrik. SVM pada awalnya digunakan untuk klasifikasi penginderaan jauh berkaitan dengan penggunaan lahan serta tutupan lahannya. Klasifikasi ini menggunakan analisa statistik univariate dan maximum likelihood dengan cara piksel yang belum diketahui identitasnya dikelompokkan berdasar vector dan matriks kovarian dari setiap pola spektral kelas. Nilai peluang piksel yang belum teridentifikasi akan dihitung oleh komputer dan dimasukkan ke dalam salah satu kelas yang peluangnya paling tinggi. (Huang et al., 2002).

\section{Normalized Difference Vegetation Index (NDVI)}

Analisis indeks vegetasi digunakan untuk mengetahui tingkat kerapatan kanopi mangrove berdasarkan respon objek pada spektrum radiasi RED dengan NIR. Indeks vegetasi merupakan persentase pemantulan radiasi matahari oleh daun yang berkorelasi dengan konsentrasi klorofil-a. Band yang digunakan dalam melakukan analisis ini menggunakan band 4 dan band 3 pada citra satelit Landsat 5, 7 sedangkan pada citra satelit Landsat 8 menggunakan band 5 dan band 4 .

$$
\mathrm{NDVI}=\frac{(\mathrm{NIR}-\mathrm{RED})}{[(\mathrm{NIR}+\mathrm{RED})}
$$

\section{HASIL DAN PEMBAHASAN}

Berdasarkan hasil analisis klasifikasi dibagi menjadi 2 kelas yaitu mangrove dan non mangrove (Gambar 2). Distribusi spasial menunjukan bahwa mangrove terdistribusi pada sungai dan daerah yang berbatasan langsung dengan perairan serti antara pulau Karimunjawa dan Kemujan. Hasil tersebut juga menunjukan bahwa telah terjadi proses regenerasi dan degradasi dari ekosistem mangrove.

Mangrove secara umum tersebar di sungai dan garis pantai yang terletak di pulau Karimunjawa dan pulau Kemujan. Berdasarkan hasil analisis di ketahui bahwa luasan mangrove pada tahun 1992 sebesar 473,94 ha, pada tahun 2003 meningkat 
menjadi 600,75 ha sedangkan pada tahun 2017 menurun menjadi 391,57 ha (Gambar 3). Faktor utama penyebab penurunan luasan mangrove antara lain penebangan liar, faktor alam, perubahan fungsi lahan menjadi pertambakan dan perhotelan. Menurut Eddy et al. (2016), kerusakan ekosistem mangrove yang ada di seluruh dunia sebagian besar disebabkan karena adanya kegiatan manusia. Ditambahkan menurut Setyawan dan Kusumo (2006), alih fungsi hutan mangrove menjadi tambak dengan hak milik perorangan maupun kelompok. Penambahan luasan mangrove terjadi pada antara tahun 1992 sampai 2003 hal tersebut disebabkan sedimentasi yang menumpuk di pantai dan sudah ditumbuhi oleh mangrove.
Secara keseluruhan metode ini dapat menggambarkan perubahan secara efektif serta hasilnya dapat dipergunakan untuk pemantauan dan perencanaan ekosistem mangrove di suatu wilayah.

Hasil klasifikasi NDVI untuk klasifikasi kerapatan berdasarkan BAPLAN (Kehutanan) dengan kerapatna jarang nilai NDVI berkisar $1-0,33$ dan kerapatan sedang nilai NDVI 0,33 - 0,42 (Baplan, 2005) tersaji pada Gambar 4. Berdasarkan hasil analisis diketahui bahwa kerapatan mangrove di Karimunjawa masuk dalam kategori jarang hingga sedang hal ini mengacu pada kriteria yang dikeluarkan oleh Baplan (2005), dominasi kerapatan mangrove di Karimunjawa kategori jarang.

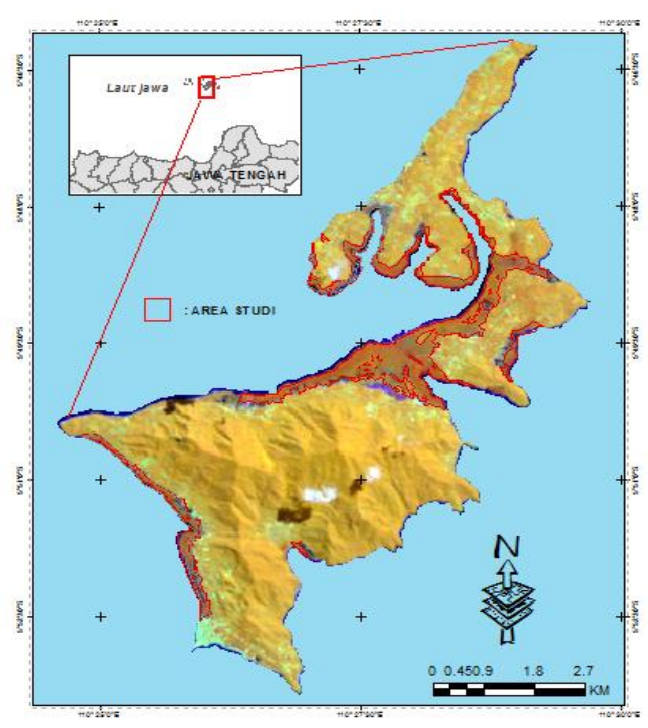

Gambar 1. Lokasi Penelitian

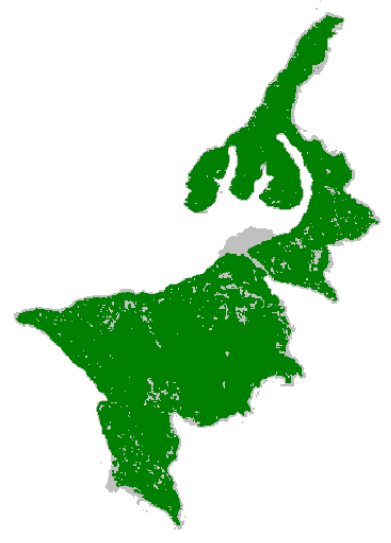

(a)

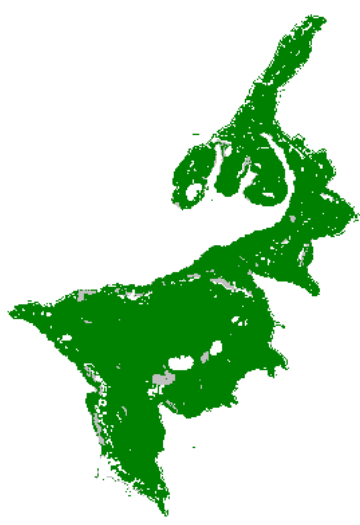

(b)

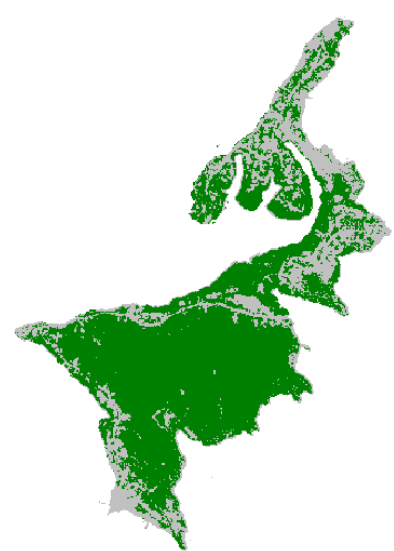

(c)

Gambar 2. Area studi setelah preprosesing yaitu vegetasi dan non vegetasi. a). Citra Landsat 1992, b). Citra Landsat 2003 dan c) Citra Landsat 2017. Keterangan : = Vegetasi, $\square=$ non vegetasi 


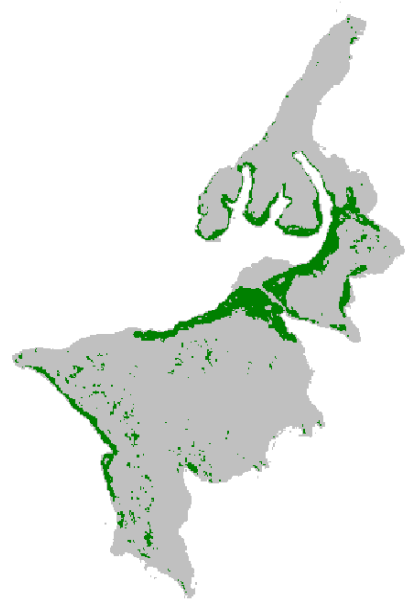

(a)

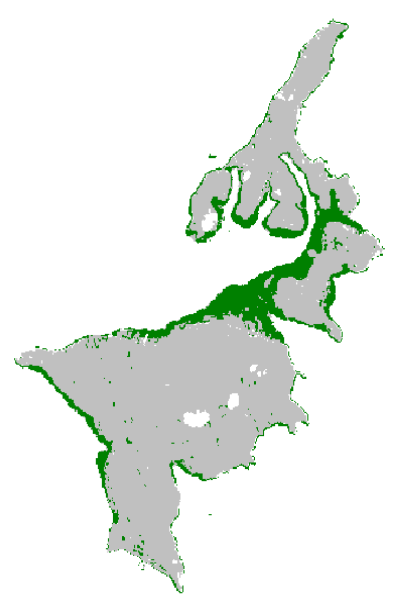

(b)

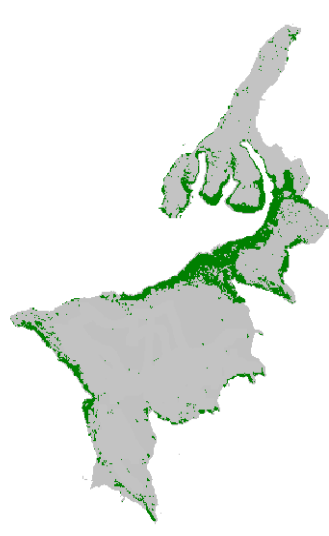

(c)

Gambar 3. Distribusi spasial ekosistem mangrove menggunakan citra Landsat 5,7,8 dari tahun 1992 -2017 , a) 1992 , b) 2003 , c) 2017 . Keterangan : $\square=$ Vegetasi, $\square=$ non vegetasi

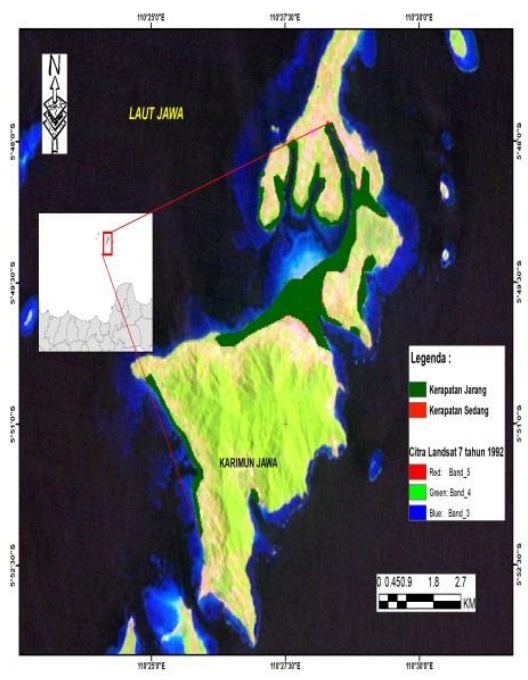

(a)

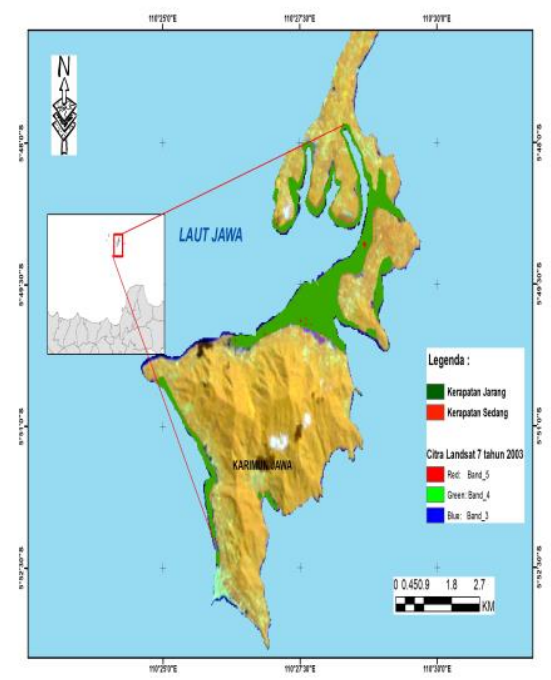

(b)

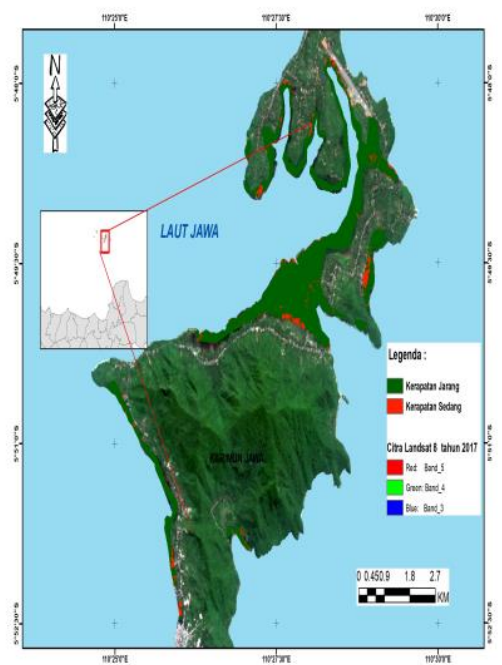

(c)

Gambar 4. NDVI kerapatan mangrove tahun 1992 (a), 2003 (b) dan 2017 (c)

\section{KESIMPULAN}

Hasil analisa spasial dengan rentang 3 tahun berbeda didapatkan perubahan adanya penurunan dan penambahan luasan tahun 1992-2003 telah terjadi penambahan luasan sebesar 126,81 ha; tahun 1992-2017 terjadi perubahan luasan sebesar 82,37 ha, tahun 2003-2017 terjadi perubahan luasan sebesar 209,18 ha. Kerapatan mangrove di Karimunjawa sebagian besar tergolong kategori kerapatan jarang dengan nilai NDVI antara 1-0,33.
Faktor utama penyebab penurunan luasan mangrove antara lain penebangan liar, factor alam, perubahan fungsi lahan menjadi pertambakan dan perhotelan. Penambahan luasan mangrove disebabkan sedimentasi yang menumpuk di pantai dan sudah ditumbuhi oleh mangrove.

\section{DAFTAR PUSTAKA}

Blasco, F., Carayon, J.L. and Aizpuru, M., 2001. World Mangrove Resources. Glomis Electronic Journal. 
Cideciyan, A.V., Jacobson, S.G., Kemp, C.M., Knighton, R.W., \& Nagel, J.H., 1992. Registration of High-Resolution Images of the Retina, Medical Imaging VI: Image Processing, 1652:310-322.

Eddy, S., M.R. Ridho, I. Iskandar, \& A. Mulyana. 2016. Community-Based Mangrove Forests Conservation for Sustainable Fisheries. J. Silvikultur Tropika. 7 (3) : 42 - 47

Europe Satelite Agency.2015. https://earth.esa.int/web/sentinel/userguides/sentinel-2-si/producttypes/level2a.

Everitt, J.H., Yang, C., Sriharan, S. \& Judd, F.W., 2008. Using high resolution satellite imagery to map black mangrove on the Texas Gulf Coast, J. Coas. Res., 24:15821586.

Giri, C., Pengra, B., Zhu, Z., Singh, A. \& Tieszen, L.L., 2007. Monitoring mangrove forest dynamics of the Sundarbans in Bangladesh and India using multi-temporal satellite data from 1973 to 2000. J. Estuar. Coas. Shelf Sci. 73:91e100.

Giri, E., Ochieng, L.L., Tieszen, Z., Zhu, A. \& Singh, T., 2011. Global Ecology and Biogeography, Global Ecology and Biogeography, 20:154-159.

Huang, C., Davis, L.S. and J.R.G., 2002. An assessment of support vector machines for land cover classification, International Journal of Remote Sensing, 23:725-749.

IIman, M., Wibisono, I. T. C., \& Suryadiputra, I. N. N. (2011). Stateoftheartinformationon mangrove ecosystems in Indonesia. Bogor: Wetlands International-Indonesia Programme.

Irons, J. R., Dwyer, J. L., \& Barsi, J. A. (2012). The next Landsat satellite: The Landsat data continuity mission. Rem. Sens. Environ. 122:11-21.

Kamal,M., Stuart Phinn and Kasper Johansen. 2015. Object-Based Approach for MultiScale Mangrove Composition Mapping Using Multi-Resolution Image Datasets. Remote Sens. 7(4):4753-4783.

Kamal, M., Hartono, Pramaditya Wicaksono, Novi Susetyo Adi, Sanjiwana Arjasakusuma. 2016. Assessment Of Mangrove Forest Degradation Through Canopy Fractional Cover In Karimunjawa
Island, Central Java, Indonesia. Geoplanning. 3(2):107-116.

Kementerian Lingkungan Hidup dan Kehutanan. 2016. Statistik Lingkungan Hidup. Jakarta: $382 \mathrm{P}$.

Kovacs, J., LU, X., Flores-Verdugo, F., Zhang, C., Flores de Santiago, F., \& Jiao, X. 2013. Applications of ALOS PALSAR for monitoring biophysical parameters of a degraded black mangrove (Avicennia germinans) forest. J. Photogram. Rem. Sens. 82:102-111.

Kuenzer, C., Bluemel, A., Gebhardt, S., Quoc, T. V., \& Dech, S. 2011. Remote sensing of mangrove ecosystems: A review. Rem. Sens., 3,878-928.

Murdiyarso, D., Purbopuspito, J., Kauffman, J. B., Warren, M. W., Sasmito, S. D., Donato, D. C., \& Kurnianto, S. 2015. The potential of Indonesian mangrove forests for global climate change mitigation. Nature Climate Change, 5, 1089-1092.

Polidoro, B. A., Carpenter, K. E., Collins, L., Duke, N. C., Ellison, A. M., Ellison, J.C., \& Koedam, N. E. 2010. The loss of species: Mangrove extinction risk and geographic areas of global concern. Plos One, $5, e 10095$.

Seto, K.C. \& Fragkias, M., 2007. Mangrove conversion and aquaculture development in Vietnam: A remote sensing-based approach for evaluating the Ramsar Convention on Wetlands, J. Global Environ. Change. 17:486-500.

Setyawan, A.D. \& W. Kusumo. 2006. Permasalahan Konservasi Ekosistem Mangrove di Pesisir Kabupaten Rembang, Jawa Tengah. J. Biodiversitas. 7(2):159 163.

Suratman, M.N. 2008. Carbon sequestration potential of mangroves in southeast Asia. Managing forest ecosystems: The challenge of climate change (pp. 297315). Springer.

Vo, Q.T., Oppelt, N., Leinenkugel, P. \& Kuenzer, C., 2013. Remote sensing in mapping mangrove ecosystems - an object-based approach. Remote Sens. 5:183-201. DOI : 10.3390/rs5010183. 